\title{
Effect of Tempering Temperature on Hardness and Impact Resistance of the 410- 1 Mo Martensitic Stainless Steels for Steam Turbine Blades
}

\author{
Efendi Mabruri ${ }^{\# 1)}$, Zefri Ahmad Syahlan, Sahlan* Moch. Syaiful Anwar, Toni B. Romijarso", \\ Bintang Adjiantoro* \\ \#Research Center for Metallurgy and Materials, Indonesian Institute of Sciences (LIPI) \\ Kawasan Puspiptek Gd. 470 Serpong, Tangerang Selatan, Indonesia \\ 1)effe004@lipi.go.id \\ *Higher Technical School of PLN \\ Menara PLN, Jl. Lingkar Luar Barat, Duri Kosambi, Cengkareng, Jakarta, Indonesia
}

\begin{abstract}
Tempering is an important process to produce the martensitic stainless steels having the desired properties. This paper reports the influence of tempering temperature on hardness and impact resistance the modified $410-1 \mathrm{Mo}$ steels. The steels samples were prepared by a process sequence of induction melting, hot forging, annealing, hardening and tempering. The tempered steels were subjected to hardness and impact testing. The experimental results showed that the hardness and the impact resistance of the steels depended strongly on tempering temperature and they changed considerably at temperature $600^{\circ} \mathrm{C}$. The secondary hardening appeared at tempering temperature around $400-550^{\circ} \mathrm{C}$. The correlation of impact energy with hardness was found to fit the linear line with negative gradient with increasing of hardness value. The fractured surfaces of the impact test specimens were analyzed using SEM images.
\end{abstract}

Keywords: martensitic stainless steels, steam turbine blades, tempering temperature, hardness, impact resistance

\section{INTRODUCTION}

During services the steam turbine blades operate within condition of high stress and high temperature erosive-corrosive environment of steams. The blades are usually made from martensitic stainless steels of $13 \mathrm{Cr}$ type $(403 / 410)$ due to its high strength, high toughness and corrosion resistance [1,2]. However, failures of the blades made from this type of steels were frequently found in the last stage of low pressure blades, particularly due to environmentally assisted craking [3,4,5,6]. Improving mechanical properties and corrosion resistance of the 13Cr type martensitic stainless steels can be accomplished by chemical composition modification and heat treatment.This type of steels should be experienced by proper heat treatment process to achieve the desired mechanical and corrosion properties. A standard heat treatment process subjected to the martensitic stainless steels consists of quenching and tempering which respectively contributes to the final properties of the steels. Quenching this type of steels from high temperature where austenite phase formed and carbide dissolution occured results in microstructure consists of mainly hard and brittle martensite, small amount of retained austenite, and may some carbides exist $[7,8]$. Tempering process should be accomplished following quenching for reducing hardness to increase ductility and toughness.

The 410-1Mo martensitic stainless steels is a modification of 410 type steels recently developed by incorportion about $1 \%$ Mo which exhibit higher tensile strength and higher elongation at breaks compared to the standard 410 type steels [9]. The heat treatment response on the properties of this steels are being investigated and a part of the results has been published elsewhere [10]. This work reports the influence of tempering temperature on hardness and charpy impact resistance of the 410-1Mo martensitic stainless steels. Fractographic analysis of impact samples and correlation between hardness and impact resistance are also presented.

\section{EXPERIMENTAL PROCEDURE}

The steel ingots of $5 \times 5 \times 10 \mathrm{~cm}$ in size were prepared by using an electric induction melting furnace. The ingots were then hot forged at around $900-1125^{\circ} \mathrm{C}$ until the cross section dimension of the ingots decreased to about $3 \times 3 \mathrm{~cm}$. The square specimens of $1 \mathrm{~cm}$ in thickness were cut from forged steels for chemical composition testing using Optical Emission Spectrometer (OES). The chemical composition of the steels is presented in Table 1 . The other parts of the forged steels were annealed at temperature $800^{\circ} \mathrm{C}$ for $20 \mathrm{~h}$ for softening to facilitate machining the samples of charpy impact test and of hardness test. The machined samples were subjected to austenizing at $1050^{\circ} \mathrm{C}$ for $1 \mathrm{~h}$ followed by quenching in oil. The austenized samples were then 
tempered at various temperature of $300,400,500,550,600,650$ and $700^{\circ} \mathrm{C}$ for $1 \mathrm{~h}$ followed by air cooling. The heat treated samples were surface ground to remove scales and machined to prepare samples for impact and hardness tests.The hardness of the steel samples was measured by Rockwell C diamond indentor of $120^{\circ}$ with indentation load and time of $15 \mathrm{Kgf}$ and 3s, respectively. The impact test was conducted at room temperature by charpy impact tester using V- notch samples with dimension of 10x10x55 mm according to ASTM E 23.The fracture surfaces images of the broken impact samples were taken by using Scanning Electron Microscope (SEM).

Table I. Chemical composition (wt. \%) of the 410-1Mo martensitic stainless steels prepared in this work.

\begin{tabular}{cccccccccc}
\hline Steel & $\mathbf{C}$ & $\mathbf{S}$ & $\mathbf{P}$ & $\mathbf{M n}$ & $\mathbf{S i}$ & $\mathbf{C r}$ & $\mathbf{M o}$ & $\mathbf{N i}$ & $\mathbf{F e}$ \\
\hline 13Cr-1Mo & 0.13 & 0.003 & 0.02 & 0.94 & 0.31 & 13.13 & 0.80 & 0.29 & Bal. \\
\hline
\end{tabular}

\section{RESULTS AND DISCUSSION}

The hardness of $13 \mathrm{Cr}-1 \mathrm{Mo}$ martensitic stainless steel after quenching at $1050^{\circ} \mathrm{C}$ and tempering at various temperature is presented in Figure 1 . At low tempering temperature $300^{\circ} \mathrm{C}$ the steel still exhibits high hardness of about 47.6 HRC. The hardness of the steel decreases to about $45.8 \mathrm{HRC}$ at tempering temperature $400^{\circ} \mathrm{C}$ and only slightly changes untill tempering at $550^{\circ} \mathrm{C}$. At tempering temperature $600^{\circ} \mathrm{C}$ the hardness of the steel significantly decrease to about $36.6 \mathrm{HRC}$ and continue to decrease at higher temperature. Finally, at the upper tempering temperature in this study of $700^{\circ} \mathrm{C}$ the steel has low hardness of about $28.8 \mathrm{HRC}$.

During tempering, the mainly microstructural evolution is the relaxation of martensite to ferrite which contributes to decreasing of hardness as tempering temperature increases. The microstructure of the tempered 410-1Mo has been reported in Ref.[10], consisted of tempered martensite, delta ferrite and carbides.The stability of hardness at temperature around $400-550^{\circ} \mathrm{C}$ as shown in Figure 1 may be attributed to secondary hardening where carbide precipitation of $\mathrm{M}_{7} \mathrm{C}$ or $\mathrm{M}_{23} \mathrm{C}_{6}$ occurs [11]. Coarsening of these stable carbides at temperature higher than $550^{\circ} \mathrm{C}$ may contribute to decreasing of the hardness [12]. Although it is not so evident, addition of about $1 \%$ Mo and slightly higher $\mathrm{Cr}$ content of this steel compared to standard 410 steels may contribute to secondary hardening. The standard 410 steels $(12 \mathrm{Cr})$ usually shows little or no secondary hardening and softening occurs at tempering temperature over $500^{\circ} \mathrm{C}[11]$.

Figure 2 shows the variation of room temperature impact resistance of the 13Cr-1Mo martensitic stainless steel with tempering temperature. It is observed that the values of impact energy as a function of tempering temperature exhibit opposite trend to the one showing by hardness values. The impact energy of the steels remain at low values until tempering temperature $550^{\circ} \mathrm{C}$ and sharply increases to about $74 \mathrm{~J}$ at temparature $600^{\circ} \mathrm{C}$. The impact energy continues to increase to $85 \mathrm{~J}$ at temperature $650^{\circ} \mathrm{C}$ and shows sharply increases again to about $127 \mathrm{~J}$ at temperture $700^{\circ} \mathrm{C}$. This high impact energy of the steel tempered at such a high temperature are strongly related to the relaxation of the martensite to the softer phase of ferrite, coarsening of the carbides and may be the formation of reversed austenite [13].

X. LIU et al [14] reported the steels with almost similar composition to the standard 410 steels tempered at $650^{\circ} \mathrm{C}$ exhibited impact energy of $100 \mathrm{~J}$ which is higher than that resulted in this work for $410-1 \mathrm{Mo}$ steel tempered at the same temperature. Meanwhile, other researcher [11] reported the martensitic stainless steel having higher content of Mo and Ni compared to the 410-1Mo steels of this work showed impact energy lower than $75 \mathrm{~J}$ at tempering temperature $650^{\circ} \mathrm{C}$, which is lower than that obtained in this work of $85 \mathrm{~J}$ for $410-1 \mathrm{Mo}$ steel. These results show that the increasing of $\mathrm{Ni}$ and Mo content in the 410 steels decreases the impact energy of the steels. However, the $410-1 \mathrm{Mo}$ steel quenched and tempered at $625^{\circ} \mathrm{C}$ directly after forging without annealing has been reported having higher tensile strength and elongation than the 410 steel [9]. Therefore, the process sequence should be optimized to achieve better properties of the 410-1Mo martensitic stainless steel. 


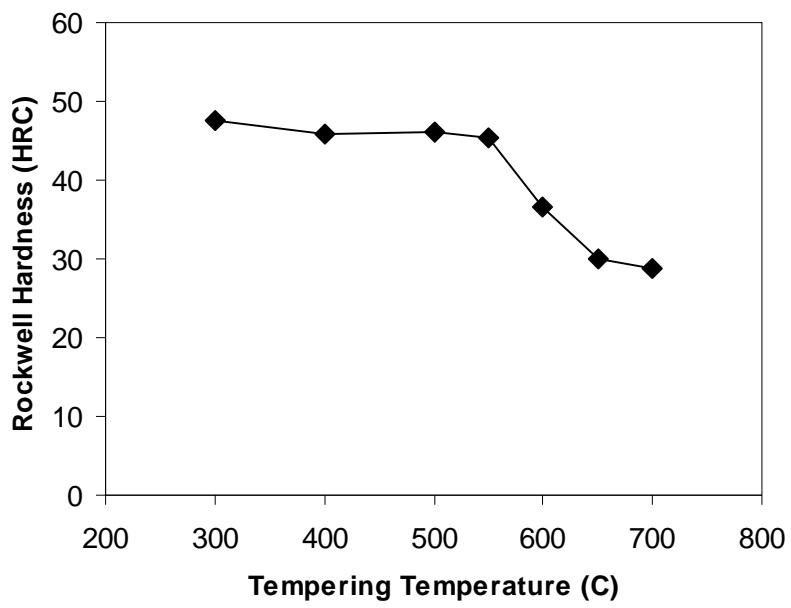

Figure 1. Hardness of 13Cr-1Mo martensitic stainless steel after tempering at various temperature.

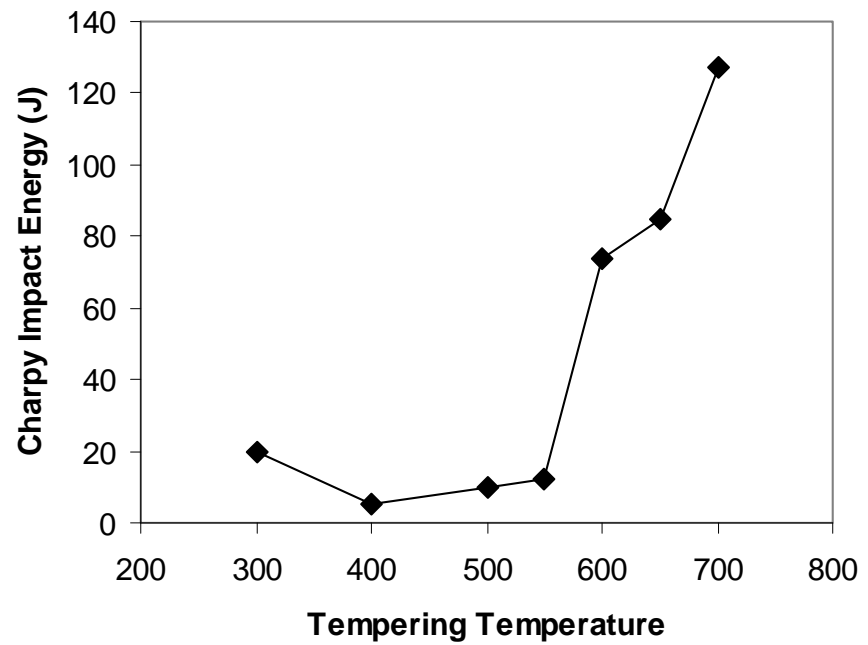

Figure 2. Impact energy of 13Cr-1Mo martensitic stainless steel after tempering at various temperature.

The correlation of impact energy with hardness of the 13Cr-1Mo steel after quenching and tempering is presented in Figure 3. It is clearly abserved from Figure 3 that the correlation of impact energy with hardness is found to fit the linear line with negative gradient with increasing of hardness value. It follows the usual role that steels with higher hardness exhibits lower impact resistance. Furthermore, with large negative gradient of -5.64 , it is worth noting that the impact resistance of the 410-1Mo steels strongly depends on the hardness value.

Figure 4 presents SEM images of the fracture surface morphology of the 410-1Mo steel after impact testing. The impact fracture surfaces of the steel tempered at $400^{\circ} \mathrm{C}$ exhibit cleavage morphology over the entire surfaces as displayed in Figure4.a indicating brittle fracture operated in the steel. The similar fracture morphology is clearly demonstrated by the steel tempered at $500^{\circ} \mathrm{C}$ (Figure 4(b)) which has relatively similar low impact resistance with the steel tempered at $400^{\circ} \mathrm{C}$ (Figure 2). As the tempering temperature increases to $600^{\circ} \mathrm{C}$, the dimple morphology exists in some small area in the fracture surface (Figure 4(c)), consistent with increasing of impact energy of the steel. The dimples become dominant with increasing tempering temperature to $700^{\circ} \mathrm{C}$ as shown in Figure 4(d) supporting respective largest impact resistance among the investigated steels. 


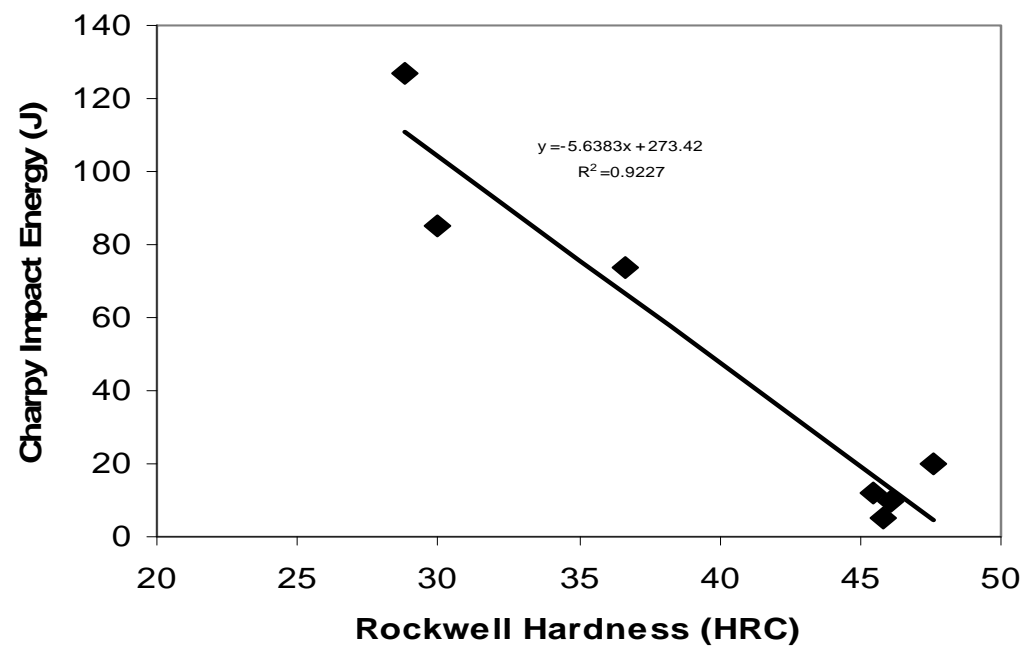

Figure 3. Correlation of impact energy with hardness of 13Cr-1Mo martensitic stinless steel after tempering.

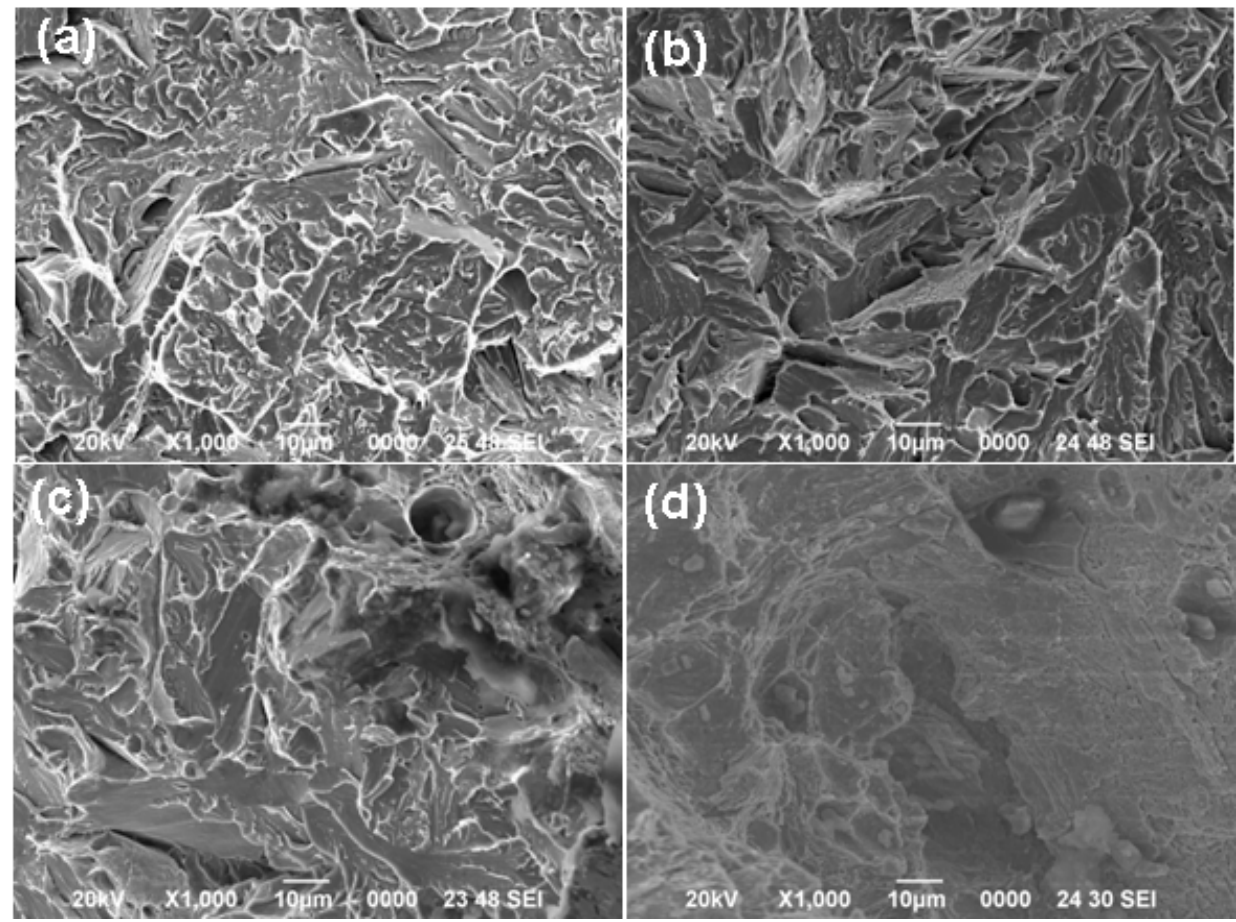

Figure 4. Impact fractured surface of the $13 \mathrm{Cr}-1 \mathrm{Mo}$ martensitic stainless steel after tempering at (a) $400^{\circ} \mathrm{C}$ (b) $500{ }^{\circ} \mathrm{C}$ (c) $600{ }^{\circ} \mathrm{C}$ (d) $700^{\circ} \mathrm{C}$

\section{CONCLUSION}

The hardness and impact energy of 410-1Mo martensitic stainless steels have been investigated with respect to tempering temperatures. The hardness and the impact resistance of the steels depended strongly on tempering temperature and they changed considerably at temperature $600^{\circ} \mathrm{C}$. The are a stability of hardness at temperature around $400-550^{\circ} \mathrm{C}$ attributed to secondary hardening due to addition of about $1 \%$ Mo and slightly higher $\mathrm{Cr}$ content of this steel compared to standard 410 steels. The impact energy continues reached a largest value about $127 \mathrm{~J}$ at tempering temperture $700^{\circ} \mathrm{C}$. The correlation of impact energy with hardness is found to fit the linear line with large negative gradient of -5.64 indicating the impact resistance of the 410-1Mo steels strongly depends on the hardness value. The steels tempered $500^{\circ} \mathrm{C}$ still exhibited cleavage morphology over the entire fractured surface, whereas the dimples morphology existed dominantly on the fractured surface of the steel tempered at $700^{\circ} \mathrm{C}$.

\section{ACKNOWLEDGEMENT}

This work is a part of the research on the development of high temperature materials for power plant. The authors thank to Research Center for Metallurgy and Materials, Indonesian Institute of Sciences (LIPI) for supporting this research. 


\section{REFERENCES}

[1] D. H. Mesa , A. Toro,A. Sinatora et al. The Effect of TestingTemperature on Corrosion-Erosion Resistance of Martensitic Stainless Steels, Wear. 255(1) (2003) 139.

[2] X.Zhu, O.Dai. M. Zhou , et al. Effect of Tempering Temperature on Stress-Corrosion Cracking and Mechanical Hysteresis of 2Crl3 Stainless Steel, Transactions of Materials and Heat Treatment. 2009. 30( I): 11 (in Chinese).

[3] P. Ralph and J. Ortolano, EPRI, CS-4001 (1985).

[4] Cuevas, J. A. Rodriguez, C. M. Clemente, J. M. Rodríguez and Y. Mariaca, Am. J. Mech. Eng. 2 (6),164-168 (2014)

[5] M. Schönbauer, S. E. Stanzl-Tschegg, A. Perlega, R. N. Salzman, N. F. Rieger, S. Zhou, A. Turnbull and D.Gandy, Int. J. Fatigue. 65, 33-43 (2014).

[6] M. M. El, T. Palin-Luca, N. Saintiera, and O. Devos, Int. J. Fatigue. 47, 330-339 (2013).

[7] C. Garcia de Andre's, L.F. Alvarez, and V. Lopez, Effects of CarbideForming Elements on the Response to Thermal Treatment of the X45Cr13 Martensitic Stainless Steel, J. Mater. Sci. 33 (1998) 4095-4100.

[8] Barlow, L. D. \& Du Toit, M. (2012). Effect of the austenitising heat treatment on the microstructure and hardness of martensitic stainless steel AISI 420. Journal of Materials Engineering and Performance, 21 (7),1327-1336.

[9] E.Mabruri, M.S.Anwar, S.Prifiharni, T.B. Romijarso, and B.Adjiantoro, Tensile properties of the modified 13Cr martensitic stainless steels, AIP Conference Proceedings 1725, 020039 (2016).

[10] S.Prifiharni, M. S.Anwar and E.Mabruri, Widyariset, 2 (1) (2016) 9 - 16.

[11] Calliari , M. Zanesco, M. Dabala, K. Brunelli, E. Ramous, Materials and Design 29 (2008) 246-250.

[12] Balan KP, Venugopal Reddy A, Sarma DS. Austenite precipitation during tempering in 16Cr-2Ni martensitic stainless steels. Scripta Mater. 39 (1998) 901-905.

[13] R.YU, D.YE , Q.YONG, J.SU, K.ZHAO, W.JIANG, J. Iron and Steel Res. Int. 18(11) (2011) 60-66.

[14] X.LIU, J.YANG, L.YANG, X.GAO, J. Iron and Steel Res. Int. 17(12) (2010) 59-64.

\section{AUTHOR PROFILE}

Dr.Efendi Mabruri He is currently working as a researcher in Research Center for Metallurgy and Materials, Indonesian Institute of Sciences. He earned Bachelor degree in Metallurgical Engineering in 1995 and Master degree in Materials Science and Engineering in 2002, both were from Bandung Institute of Technology (ITB), Indonesia. The Doctor degree in Materials Science and Engineering was earned in 2008 from Nagoya University, Japan. 